\title{
Optimizing Repeat-Visit, Call-Broadcast Nocturnal Surveys for Yellow Rails (Coturnicops noveboracensis)
}

Author(s): Kristen Martin , Nicola Koper and Ron Bazin

Source: Waterbirds, 37(1):68-78. 2014.

Published By: The Waterbird Society

DOI: http://dx.doi.org/10.1675/063.037.0109

URL: http://www.bioone.org/doi/full/10.1675/063.037.0109

BioOne (www.bioone.org) is a nonprofit, online aggregation of core research in the biological, ecological, and environmental sciences. BioOne provides a sustainable online platform for over 170 journals and books published by nonprofit societies, associations, museums, institutions, and presses.

Your use of this PDF, the BioOne Web site, and all posted and associated content indicates your acceptance of BioOne's Terms of Use, available at www.bioone.org/ page/terms_of_use.

Usage of BioOne content is strictly limited to personal, educational, and noncommercial use. Commercial inquiries or rights and permissions requests should be directed to the individual publisher as copyright holder. 


\title{
Optimizing Repeat-visit, Call-broadcast Nocturnal Surveys for Yellow Rails (Coturnicops noveboracensis)
}

\author{
Kristen Martin ${ }^{1}$, Nicola Koper ${ }^{1, *}$ and Ron Bazin ${ }^{2}$ \\ ${ }^{1}$ Natural Resources Institute, University of Manitoba, Winnipeg, Manitoba, R3T 2M6, Canada \\ ${ }^{2}$ Canadian Wildlife Service, Environment Canada, 150-123 Main Street, Winnipeg, Manitoba, R3C 4W2, Canada \\ *Corresponding author; E-mail: Nicola.koper@ad.umanitoba.ca
}

\begin{abstract}
Due to its secretive nature and nocturnal vocalization, multi-species bird monitoring programs are not effective in surveying populations of Yellow Rails (Coturnicops noveboracensis) and, thus, species-specific survey methods should be used. To determine how to optimize nocturnal call-playback surveys of Yellow Rails, we evaluated the effects of survey methods (naïve-estimated vs. detectability-adjusted estimated occupancy, observer, number of surveys, and the use of playbacks) and temporal and environmental conditions (e.g., time, date, temperature, moon phase, seasonality, and cloud cover) on detection probability. In 2010 and 2011, 334 call-broadcast night surveys for Yellow Rail were conducted at 167 survey points within 80 wetlands in south-central Manitoba, Canada. Yellow Rail detection probability was estimated at 0.63 in both years. In 2010, the detectability-adjusted wetland occupancy rate was estimated at 0.63 , and in 2011 it was estimated at 0.36 . Call-broadcast surveys contributed relatively little to improving Yellow Rail detectability, but repeat surveys at each site increased the number of individuals detected. Detection probability was not correlated with the temporal or environmental variables we studied, or by observer. Surveys where call-broadcasts are not feasible, such as volunteer surveys, are still likely to result in good estimates of Yellow Rail abundances, if surveys are repeated within breeding seasons. Received 25 September 2012, accepted 8 November 2013.
\end{abstract}

Key words._Coturnicops noveboracensis, double-observer, marsh bird surveys, occupancy models, Yellow Rail. Waterbirds 37(1): 68-78, 2014

The Yellow Rail (Coturnicops noveboracensis) has been listed as a species of Special Concern in Canada (Committee on the Status of Endangered Wildlife in Canada 2001, 2009) and as a species of Special Management Concern in the United States (U.S. Fish and Wildlife Service 2002). In Canada, population sizes and trends for this species are based on crude estimates for most provinces (Alvo and Robert 1999). Most populations are believed to have declined and may still be declining (Alvo and Robert 1999; Committee on the Status of Endangered Wildlife in Canada 2009), but much of the uncertainty associated with population sizes and trends is due to challenges associated with surveying for Yellow Rails. Common long-term avian census programs, such as the North American Breeding Bird Survey (Sauer et al. 2012), do not effectively sample Yellow Rails because relatively little wetland area, compared with other habitat types, is intersected by road surveys, and because Yellow Rails primarily vocalize at night (Herkert 1995; Robert 1997; Ribic et al. 1999). Thus, a special survey effort is required for Yellow Rails. Survey protocols targeting Yellow Rails (e.g., Bazin and Baldwin 2007) recommend that multiple-visit, call-broadcast night surveys be used. However, studies testing these survey methods and the conditions under which they are effective (e.g., Prescott $e t$ al. 2002) are limited, and need to be repeated in other parts of the species' range. Further, the effects of observer, number of surveys, and the use of playbacks on detection probability need to be assessed to optimize surveys for Yellow Rails.

Call-broadcast has become standard in marsh bird survey methods (Conway 2009). This survey method, which involves playing recorded calls of the target species to elicit vocal responses, has been used to survey marsh birds for several decades (Glahn 1974; Johnson and Dinsmore 1986). Compared to passive listening surveys, the use of conspecific call-broadcast has increased detections of many species of rails and bitterns (Gibbs and Melvin 1993; Lor and Malecki 2002; Allen et al. 2004; Conway and Gibbs 2005). However, it is not known whether the effectiveness of call-broadcast for detecting Yellow Rails outweighs the additional time, effort, training and equipment required to 
conduct call-broadcast compared with passive-listening surveys.

The effectiveness of surveys for secretive marsh birds is partly influenced by the focal species' detection probability. Most species exhibit imperfect detection: individuals that are present at a site may not always be detected during surveys (MacKenzie et al. 2002). Knowledge of a species' detection probability is necessary for determining the number of surveys required (MacKenzie et al. 2002; MacKenzie and Royle 2005). If too few survey visits are used, or if listening or playback periods are too short, sites may be falsely classified as unoccupied by the species (Tyre et al. 2003; MacKenzie 2005; MacKenzie and Royle 2005; MacKenzie et al. 2006). Conversely, if a single survey visit is sufficient, repeat site visits needlessly consume financial and personnel resources that could be better devoted to increasing the study sample size by surveying additional sites.

Finally, temporal and environmental factors and observer effects can influence a species' detectability and, therefore, survey effectiveness. To obtain accurate data on population sizes and trends, surveys should coincide with the peak vocalization period of the target species, which varies seasonally (Rehm and Baldassarre 2007). Furthermore, the detection probability of marsh birds is often not constant throughout a daily survey period. This has been shown for Black Rails (Laterallus jamaicensis; Spear et al. 1999), and Least (Ixobrychus exilis) and American Bitterns (Botaurus lentiginosus; Gibbs and Melvin 1993). Environmental factors such as temperature and wind can also influence the detection probability of marsh bird species (Gibbs and Melvin 1993; Legare et al. 1999; Spear et al. 1999). In addition, because Yellow Rails vocalize at night, their detectability may be influenced by factors that affect ambient light levels, such as cloud cover, moon phase and moon visibility (Spear et al. 1999; Mougeot and Bretagnolle 2000). Although Prescott et al. (2002) found little influence of temporal and environmental variables on Yellow Rails in Alberta, it is unknown whether these variables are influential in other parts of their range. Finally, the detection probability of a species may be influenced by observer behavior or ability (Conway et al. 2004; Nadeau et al. 2008).

Our objectives were to evaluate the effects of survey methods (naïve-estimated vs. detectability-adjusted estimated occupancy, observer, number of surveys, and the use of playbacks) and temporal and environmental conditions (e.g., time, date, temperature, moon phase, seasonality, and cloud cover) on detection probability of Yellow Rails, to help inform future survey methods and monitoring programs for this species at risk.

Methods

Study Area

The study area consisted of wetlands $(n=80)$ in south-central Manitoba (Fig. 1). Study wetlands were characterized by the presence of wetland vegetation (Stewart and Kantrud 1971), such as sedge (Carex spp.) and rush (Juncus spp.), and $88 \%$ of the wetlands had areas of open water. Some wetlands also included a shrub component, such as willow (Salix spp.), but grasslike wetland vegetation was predominant. Adjacent wetlands separated by upland vegetation were considered two separate wetlands. The study area included two different ecoregions: the Interlake Plain and the Lake Manitoba Plain (Ecological Stratification Working Group 1995), in which Yellow Rails were known to occur but in which their abundance was unknown. Upland vegetation in the Interlake Plain ecoregion was dominated by shrubs, trembling aspen (Populus tremuloides) and balsam poplar (P. balsamifera), while common upland vegetation types of the Lake Manitoba Plain ecoregion included oak (Quercus spp.) and trembling aspen intermixed with fescue (Festuca spp.) grasslands (Ecological Stratification Working Group 1995).

Site Selection

Of the wetlands we surveyed $(n=80)$, 44 were surveyed in 2010, and 36 were surveyed in 2011. Although random wetland selection would better represent the variation in wetland types found in the study area, random selection of study sites can be problematic if the target species is uncommon, as the species may not be detected at any of the randomly selected sites (Gibbs and Melvin 1997). Further, evaluating what taxa of vegetation are required by this species was not a priority of this study, as vegetation requirements have already been described (Stenzel 1982; Popper and Stern 2000); therefore, only wetlands that contained habitat suitable for Yellow Rails were studied. When we initiated this study, it was unknown whether Yellow Rails were rare or widely distributed among apparently suitable wetlands in our study area. To increase the probability of sampling an adequate number of wetlands occupied by Yellow Rails, 


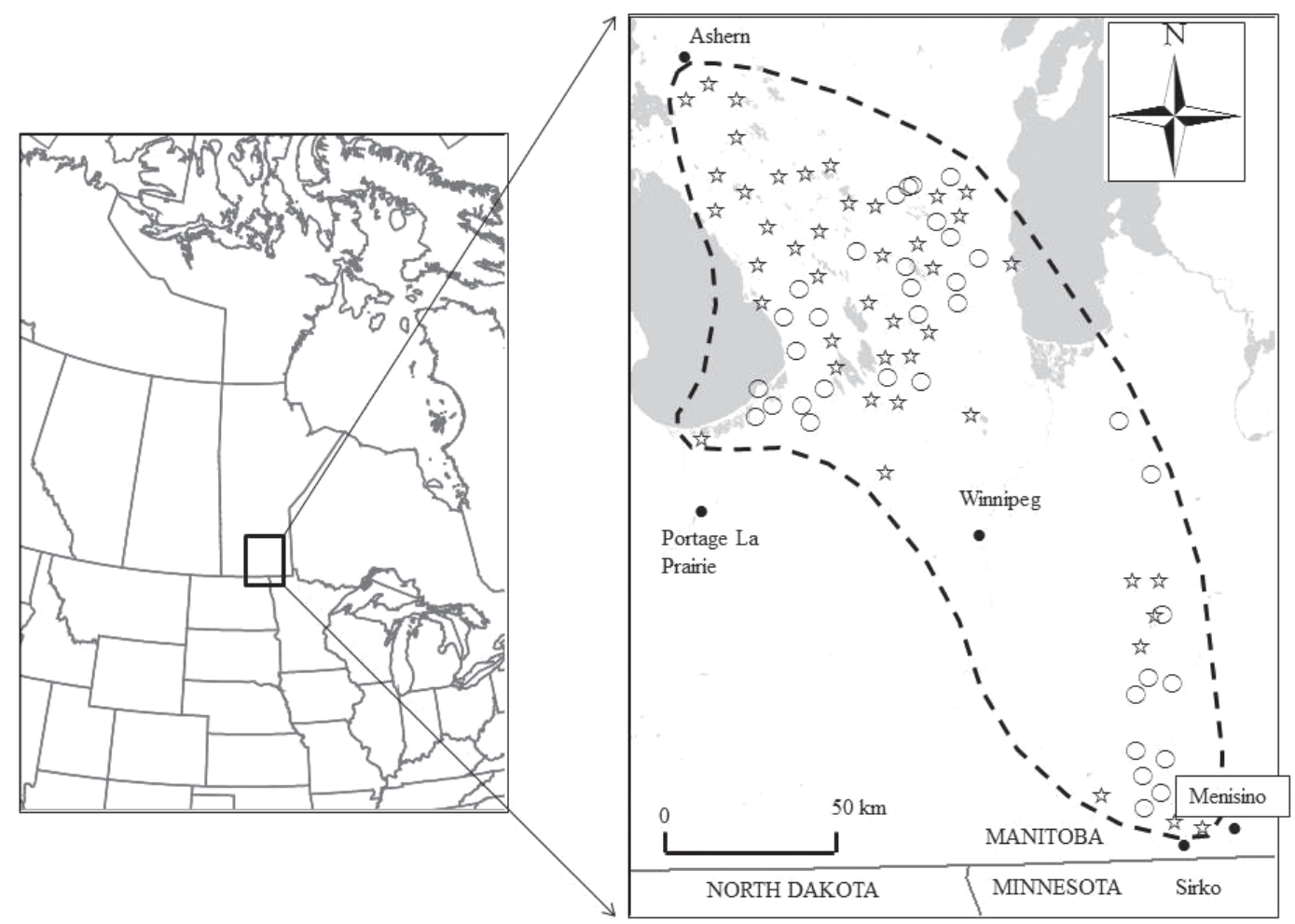

Figure 1. Study area consisting of 80 wetlands in south-central Manitoba. Wetlands surveyed for Yellow Rails (Coturnicops noveboracensis) in 2010 are denoted by circles; those surveyed in 2011 are denoted by stars.

and allowing an evaluation of the effects of repeated visits and environmental conditions on detectability of Yellow Rails, study wetlands were selected both opportunistically and using a stratified random approach. All wetlands $(n=10)$ within the study area at which Yellow Rail presence had been confirmed in previous breeding seasons (as long ago as 1937) were surveyed (Table 1). We randomly selected the remaining wetlands $(n=$ 70) from among the wetlands available in the region. All surveyed wetlands contained sedges, rushes, and/ or grasses (Poacea), which are known to support Yellow
Rails (Elliot and Morrison 1979; Stenzel 1982; Popper and Stern 2000). Wetlands were separated by $6 \mathrm{~km}$ to ensure independence among wetlands.

Locations of potentially suitable wetlands were determined using a GIS habitat-type layer; these potential sites were visited by vehicle, and the occurrence of suitable vegetation was evaluated visually. Study wetlands were then randomly selected from this pool of available wetlands. Welch's $t$-tests (SAS Institute, Inc. 2008) were used to evaluate whether wetland size, water depth, and $\%$ Cyperaceae, Poaceae, Juncus, cattail (Typha spp.), and

Table 1. Locations of wetlands $(n=10)$ surveyed in south-central Manitoba in 2010, where the presence of Yellow Rails (Coturnicops noveboracensis) had been documented in previous breeding seasons. WMA = wildlife management area.

\begin{tabular}{|c|c|c|c|}
\hline Site Name & Latitude & Longitude & Information Source \\
\hline Tall Grass Prairie Preserve & $49^{\circ} 13^{\prime} 35.96^{\prime \prime}$ & $96^{\circ} 45^{\prime} 32.56^{\prime \prime}$ & Local Birdwatcher \\
\hline Sundown Bog & $49^{\circ} 6^{\prime} 16.06^{\prime \prime}$ & $78^{\circ} 22^{\prime} 18.69^{\prime \prime}$ & Local Birdwatchers/Biologists \\
\hline Richer & $49^{\circ} 39^{\prime} 26.78^{\prime \prime}$ & $78^{\circ} 26^{\prime} 2.61^{\prime \prime}$ & Manitoba Conservation Data Centre \\
\hline PR 501, Ste. Genevieve & $49^{\circ} 45^{\prime} 6.31^{\prime \prime}$ & $78^{\circ} 30^{\prime} 50.59^{\prime \prime}$ & Local Birdwatchers \\
\hline Brokenhead Swamp & $49^{\circ} 44^{\prime} 56.89^{\prime \prime}$ & $78^{\circ} 24^{\prime} 41.12^{\prime \prime}$ & Local Birdwatchers \\
\hline Grant's Lake WMA & $50^{\circ} 3{ }^{\prime} 49.52^{\prime \prime}$ & $79^{\circ} 32^{\prime} 32.18^{\prime \prime}$ & Fryer (1937) \\
\hline Oak Hammock WMA & $50^{\circ} 11 ' 48.40^{\prime \prime}$ & $79^{\circ} 9^{\prime} 38.09^{\prime \prime}$ & Birdwatchers, Holland and Taylor (2003) \\
\hline Little Birch WMA & $51^{\circ} 6^{\prime} 41.34^{\prime \prime}$ & $80^{\circ} 15^{\prime} 19.73 "$ & Local Birdwatcher/Biologist \\
\hline Marshy Point & $50^{\circ} 31^{\prime} 16.93 ”$ & $80^{\circ} 2^{\prime} 26.64^{\prime \prime}$ & Local Birdwatcher/Biologist \\
\hline $3 \mathrm{~km} \mathrm{NE}$ of Lundar & $50^{\circ} 43^{\prime} 50.13^{\prime \prime}$ & $80^{\circ} 1^{\prime} 5.98^{\prime \prime}$ & Manitoba Conservation Data Centre \\
\hline
\end{tabular}


shrub cover differed between the new sites $(n=70)$ and the wetlands at which Yellow Rails had previously been recorded $(n=10)$. Study wetlands ranged from 0.81 ha to $1,882 \mathrm{ha}$; in general, our results are applicable to wetlands in this size range and that contain habitat suitable for Yellow Rails.

\section{Survey Points}

A map of each wetland was created in ArcMap (Environmental Systems Research Institute 2010) using land cover type layers and a waterbody inventory layer (Manitoba Land Initiative 2001, 2002). Random survey locations were selected using GIS, and were separated by a minimum of $400 \mathrm{~m}$ to reduce the probability of double-counting individual Yellow Rails (Conway 2009). Survey points were added until each wetland was saturated with survey points, or until a maximum of eight survey points was established. Upon the first field visit, survey points located in unsuitable or inaccessible habitat (e.g., in deep water or a thick cattail patch) were relocated to the nearest suitable habitat if possible, or eliminated if relocation to suitable habitat that was at least $400 \mathrm{~m}$ away from other survey points was not possible. Because surveys were conducted at night, survey points were situated within $900 \mathrm{~m}$ of road access for researcher safety concerns. For large wetlands that could not be completely surveyed due to these constraints, only a portion of the wetland was surveyed. In total, 167 survey points were established within the study wetlands (Range $=1$ to 8 points $/$ wetland, mean $=2.2$ points $/$ wetland). Seven of these points were interior wetland points in large, shallow wetlands where access (on foot) to the wetland interior was possible; all other points were located near the wetland perimeter.

\section{Call-broadcast Surveys}

The call-broadcast method was used to survey for Yellow Rails (e.g., Lor and Malecki 2002; Prescott et al. 2002; Allen et al. 2004; Conway 2009). The Canadian Wildlife Service Standardized Protocol for the Survey of Yellow Rails in Prairie and Northern Region (Bazin and Baldwin 2007) was followed as its scope includes south-central Manitoba, and it employs survey methods that are consistent with wider-ranging marsh bird survey protocols, such as the Standardized North American Marsh Bird Monitoring Protocols (Conway 2009).

Each survey was $10 \mathrm{~min}$ in length, and consisted of a 5-min passive-listening period, followed by a 3 -min conspecific call-broadcast period, and a final 2-min passivelistening period (Bazin and Baldwin 2007). Each minute of the call-broadcast period consisted of $30 \mathrm{sec}$ of broadcasted Yellow Rail clicking vocalizations (Brigham 1994) followed by $30 \mathrm{sec}$ of silence (Bazin and Baldwin 2007). The same Yellow Rail vocalization sequence was used for all surveys. The vocalizations were broadcast from a game caller (Western Rivers) facing the wetland center, at approximately $70 \mathrm{~dB}$ (measured 1-m in front of the speaker). Surveys were initiated upon arrival at the survey point (Conway 2009). Each 10-min survey period was sub-divided into 1-min counting blocks (Bazin and Baldwin 2007). To keep track of individual Yellow Rails, the distance $(0-25 \mathrm{~m}, 25-50 \mathrm{~m}, 50-75 \mathrm{~m}, 75-125$ $\mathrm{m}, 125-200 \mathrm{~m}$, or $>200 \mathrm{~m}$ ) and direction of each vocalizing Yellow Rail from the survey point were estimated (Bazin and Baldwin 2007). The vocalizing activity (i.e., vocalizing or not vocalizing) was noted for each Yellow Rail during each minute and immediately prior to and after the survey.

In both years, two repeats of Yellow Rail surveys were conducted at each site, between 23 May and 5 July, which corresponds with the most active vocalization period for Yellow Rails in the study region (Holland and Taylor 2003; Bazin and Baldwin 2007). In 2010, wetlands were surveyed once between 23 May and 15 June and again between 16 June and 5 July. The length of time between the first and second surveys of each wetland ranged from 14 to 40 days, with a mean of 22 days. In 2011, wetlands were surveyed once between 24 May and 14 June and again between 15 June and 1 July 2011. The length of time between the two surveys ranged from 10 to 33 days, with a mean of 20 days. Surveys were restricted to between $1 \mathrm{hr}$ after sunset and $1 \mathrm{hr}$ before sunrise, to correspond with highest Yellow Rail vocal activity (Bazin and Baldwin 2007). Prior to initiating each survey, ambient temperature was measured. The moon phase (e.g., new, full), moon visibility (e.g., visible, obscured), percent of the sky covered by clouds in categories $(0 \%, 1-25 \%, 26-50 \%, 51-75 \%, 76-99 \%$ or $100 \%)$, and Beaufort wind speed were also noted at the start of each survey. Surveys were not conducted during heavy rain or wind speeds of Beaufort 4 or greater (Bazin and Baldwin 2007). Wetlands were surveyed following a random order, adjusted where necessary to ensure that there was no trend in location or wetland size, which might bias our results if there were seasonal effects on detectability.

All surveys in 2010 and all May-June surveys in 2011 were conducted using the same two observers, with both observers contributing Yellow Rail detections to the survey. In 2011, the double-observer method (Nichols et al. 2000) was used for all June-July surveys to determine if observer identity affected the probability of detecting Yellow Rails during night surveys. For the double-observer surveys, one observer was randomly designated as the primary observer and the other as the secondary observer each night (Nichols et al. 2000). The primary observer would announce all of the birds that they heard and the birds' initial distances and directions from the survey point (Nichols et al. 2000). Both observers recorded this information on separate data sheets. In addition to all of the primary observer's observations, the secondary observer recorded all of the birds they detected that were missed by the primary observer (Nichols et al. 2000). The secondary observer always stood behind the primary observer during surveys to avoid indirectly informing the primary observer about additional birds that were missed (Nichols et al. 2000). The observers alternated between primary and secondary roles each night (Nichols et al. 2000). While only those surveys conducted using the double-observer method (i.e., JuneJuly 2011) were used to quantify observer effects, all four surveys in 2010-2011 were used in all other analyses. 


\section{Analysis}

For each survey round, the percent increase in Yellow Rails detected following the start of the call-broadcast segment was calculated. We also wanted to understand whether returning to the original survey locations later in the breeding season would increase occupancy estimates. The percent increase in the number of survey points at which Yellow Rails were detected as a result of the second survey round was calculated.

Yellow Rail detection probability, detectabilityadjusted wetland occupancy, and variation in detectability between rounds were calculated in the software program PRESENCE (Bailey et al. 2007). We defined naïve-estimated occupancy as wetlands or points at which detectability was not statistically adjusted to account for detectability, and detectability-adjusted wetland occupancy as occupancy estimated using PRESENCE to statistically control for imperfect detectability. Detection probability and the resulting detectabilityadjusted estimated wetland occupancy were estimated for 2010 ( $n=44$ wetlands) and 2011 ( $n=36$ wetlands) separately, as different wetlands were surveyed in each year. Because PRESENCE does not allow for the use of random variables, which would otherwise allow us to account for correlations among point counts within the same wetlands, we collapsed data within each wetland into a single value of occupancy per wetland. To allow us to determine whether detectability varied between rounds, two candidate models were tested in PRESENCE: one holding detection probability constant over the two survey rounds, and the other allowing detection probability to vary between the two survey rounds. For each year, the model that best explained Yellow Rail detection probability was selected using Akaike's Information Criterion, corrected for small sample size (AIC; Burnham and Anderson 2002).

A generalized linear mixed model (GLMM; PROC GLIMMIX; SAS Institute, Inc. 2008) was used to determine if the number of Yellow Rails detected per survey point varied with ambient temperature, moon phase, moon visibility, cloud cover, Beaufort wind speed, Julian date, year, and time since sunset. Moon phase was classified on a scale from 0 (new moon) to 4 (full moon), and moon visibility was classified on a scale from 0 (moon absent) to 2 (moon visible). Time since sunset was the number of minutes between sunset in Winnipeg, Cana$\mathrm{da}$, and the survey start time. The interaction between moon phase and moon visibility was included to evaluate the effect of ambient light on Yellow Rail detectability. To determine if temporal effects were nonlinear, quadratic effects of date and time since sunset were also evaluated.

A Poisson distribution was used to describe the distribution of the response variable, the number of Yellow Rails detected per survey point, as a Poisson model is appropriate for count data (Quinn and Keough 2002), and because the model did not converge when a negative binomial distribution was specified. Wetland ID was included as a random effects variable, to control for correlations among plots within wetlands. We initially also included survey point as a random variable, but the estimate of its effect size was very small, suggesting that it did not explain additional variation in the data. Including survey point as an additional random variable also frequently led to the model's failure to converge, presumably because the model was over-parameterized. Survey point was, therefore, excluded from the final model. An $\alpha$-level of 0.1 was used to reduce the probability of Type II error.

To evaluate whether variables were collinear, prior to the final analyses we calculated correlations among the independent variables, using Spearman's rank correlation coefficient $\left(r_{\mathrm{s}}\right)$ because the distributions of the variables were not normal. As expected, temperature and Julian date were correlated $\left(r_{\mathrm{s}}=0.73, P=<0.001\right)$. However, because this correlation was less than $r_{\mathrm{s}}=$ 0.75 , and because excluding influential variables can result in misleading conclusions about the effect and significance of variables with which they are correlated (Smith et al. 2009), both variables were still included in the model. No other variables were highly correlated.

When quantifying detectability, the dataset was limited to surveys at points where Yellow Rails were detected at least once $(n=150$ surveys). Including survey points at which Yellow Rails were never detected could have biased the results, as those survey points would have been interpreted as points where Yellow Rails were present, but not detected (Conway et al. 2004; Conway and Gibbs 2005; Rehm and Baldassarre 2007). Yellow Rails that were detected while walking between survey points but not during surveys were not included in the analysis.

The program DOBSERV (Hines 2000) was used to calculate observer detection probability. Two standard candidate models were tested in DOBSERV on the June-July surveys conducted in 2011: one model holding observer detection probability the same for both observers, and the other allowing observer detection probability to vary with observer. $\mathrm{AIC}_{\mathrm{c}}$ was used to select the best-fitting model.

\section{Results}

Wetland size, water depth, and percent Cyperaceae, Poaceae, Juncus, cattail, and shrub cover were not significantly different between the new sites $(n=70)$ and the wetlands $(n=10)$ at which Yellow Rails had previously been recorded $(P>0.134)$. More Yellow Rails were detected in 2010 than in 2011 in both the May-June and June-July surveys (Table 2). In both years, the number of Yellow Rails detected per survey point ranged from 0 to 4 . Most Yellow Rail detections $(78 \%$; $n=$ 204) occurred within the first survey minute (Fig. 2). In 2010, 17\% and 6\% more Yellow Rails were detected during and following the call-broadcast segment than prior to the 
Table 2. Numbers of Yellow Rails (Coturnicops noveboracensis $)$ detected at point-count plots $(n=167)$ within wetlands $(n=80)$ during night surveys in south-central Manitoba in 2010 and 2011. In 2010, surveys were conducted from 23 May to 15 June, and from 16 June to 5 July. In 2011, surveys were conducted from 24 May to 14 June and from 15 June to 1 July.

\begin{tabular}{lcc}
\hline \hline Year & $\begin{array}{c}\text { Yellow Rails } \\
\text { Detected in } \\
\text { May-June Survey }\end{array}$ & $\begin{array}{c}\text { Yellow Rails } \\
\text { Detected in } \\
\text { June-July Survey }\end{array}$ \\
\hline 2010 & 88 & 69 \\
2011 & 31 & 16 \\
\hline
\end{tabular}

call-broadcast segment, during the May-June and June-July surveys, respectively (Fig. 2). In 2011, no new individuals were detected following the start of the call-broadcast segment in the May-June surveys, but $14 \%$ more Yellow Rails were detected following initiation of the call-broadcast in the June-July surveys. On average, $10 \%$ of first detections of Yellow Rails occurred at or after initiation of the call-broadcast in each survey (Fig. 2).

Yellow Rails did not respond immediately to the conspecific call-broadcast segment, but new Yellow Rails were detected throughout the entire 3-min call-broadcast segment and during the final passive listening period (Fig. 2). After initiation of the call-broadcast sequence, $4 \%$ of the Yellow Rails detected prior to the call-broadcast segment had stopped vocalizing. Use of call-broadcast increased the number of survey points at which Yellow Rail presence was confirmed by $1.4 \%$ in 2010 and by $0.8 \%$ in 2011 , but

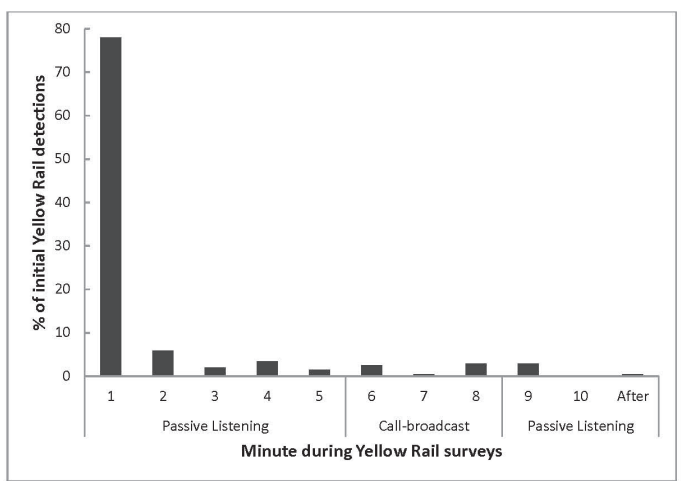

Figure 2. Survey minute in which individual Yellow Rails (Coturnicops noveboracensis) were initially detected during night surveys conducted in south-central Manitoba in 2010-2011. did not increase the number of wetlands at which Yellow Rail presence was confirmed in either year of the study.

Over the study, Yellow Rail presence was confirmed at $44 \%$ of wetlands surveyed $(n=$ 80 wetlands). Surveying each wetland twice increased the number of survey points at which Yellow Rails were detected by $9.2 \%$ in 2010 and by $3.5 \%$ in 2011 and increased the number of wetlands at which Yellow Rails were detected by $11.4 \%$ in 2010 and by $5.5 \%$ in 2011. Of the 35 wetlands at which Yellow Rail presence was detected in the 2-year study, Yellow Rails were heard at $46 \%$ of the wetlands in both surveys.

Detection probability and detectabilityadjusted estimated wetland occupancy were similar within and among years (Table 3). In 2010, the detection probability for Yellow Rails was estimated to be $0.63(\mathrm{SE}=0.10)$, and the detectability-adjusted wetland occupancy rate was estimated to be 0.63 (SE $=0.10), 16 \%$ higher than the naïve occupancy rate of 0.55 . For the 2011 dataset, the detection probability for Yellow Rail was estimated to be $0.63(\mathrm{SE}=0.14)$, and the detectability-adjusted wetland occupancy rate was estimated to be $0.36(\mathrm{SE}=0.10)$, $18 \%$ higher than the naïve occupancy rate of 0.31 . In both years, the $95 \%$ confidence intervals of the detectability-adjusted estimated wetland occupancy encompassed the naïve estimated occupancy rate $(95 \%$ $\mathrm{CI}=0.43-0.83$ in $2010 ; 95 \% \mathrm{CI}=0.17-0.56$ in 2011). The number of Yellow Rail detections was not significantly affected by any of the temporal or environmental covariates tested (Table 4). There was no quadratic relationship between the number of Yellow Rails detected and date $\left(\beta=-1.5 \times 10^{-6}, P=\right.$ $0.99)$ or time since sunset $\left(\beta=-1.0 \times 10^{-5}\right.$, $P=0.36)$.

The double-observer approach was used at 58 plots in 2011. Yellow Rails $(n=16)$ were detected at 10 plots. Of the two candidate models tested in program DOBSERV (Hines 2000), the model assuming detection probability was the same for both observers best explained the data (Table 5; Arnold 2010). Observer detection probability $( \pm \mathrm{SE})$ for both observers was high: $0.98 \pm 0.03$. 
Table 3. AIC $_{\mathrm{c}}$ values and weights for candidate models tested in PRESENCE (Hines 2000) to estimate Yellow Rail (Coturnicops noveboracensis) detection probability and detectability-adjusted estimated wetland occupancy at 80 wetlands located in south-central Manitoba; $n=$ number of wetlands. Forty-four wetlands were surveyed in 2010, and 36 were surveyed in 2011.

\begin{tabular}{lcccccc}
\hline \hline Model & Year & $n$ & $K$ & $-2 *$ LogLikelihood & $\Delta$ AIC $_{\mathrm{c}}$ & AIC $_{\mathrm{c}}$ Weight \\
\hline Constant detection probability & 2011 & 36 & 2 & 67.790 & 0 & 0.702 \\
Constant detection probability & 2010 & 44 & 2 & 111.760 & 0 & 0.691 \\
Survey-specific detection probability & 2010 & 44 & 3 & 111.060 & 1.610 & 0.309 \\
Survey-specific detection probability & 2011 & 36 & 3 & 67.110 & 1.710 & 0.298 \\
\hline
\end{tabular}

Discussion

We detected new Yellow Rails throughout the 10-min listening period, although the occurrence of new individuals declined dramatically after the first minute. Although the detection of Yellow Rails increased by $10 \%$ on average after the callbroadcast was initiated, Fig. 2 shows that there was no increase in the rate of additional detections upon initiation of the call-playback period, compared with the numbers of new individuals detected in minutes 2-5. Thus, there is little evidence that call-broadcasts actually caused the additional detections. The magnitudes of the increases following initiation of callbroadcasts ( $<20 \%$ for each survey round) were similar to the $19.6 \%$ increase in Yellow Rails detected during and following call-broadcast used in night surveys in a study in Alberta (Prescott et al. 2002). In both cases, it is possible that call-broadcast might have coincided with, but not caused, new calls from previously undetected individuals.
Conway and Nadeau (2010) found that call-broadcast increased the number of Yellow Rail detections by $112 \%$ during morning and evening surveys, and many other species of secretive marsh birds have shown much higher responses to call-broadcast during their primary vocalization periods. For example, call-broadcast (using multiple species' calls) has been shown to increase the number of Soras (Porzana carolina) detected by $>100 \%$ (Lor and Malecki 2002; Allen et al. 2004), Virginia Rails (Rallus limicola) by $>400 \%$ (Lor and Malecki 2002; Allen et al. 2004) and King Rails (R. elegans) by $>1000 \%$ (Allen et al. 2004). However, passive listening resulted in more accurate Water Rail (Rallus aquaticus) population estimates than did call-broadcast (Stermin et al. 2013), and, thus, call-broadcast does not increase detections in all cases.

Differences in the number of Yellow Rails detected between surveys in both years indicate Yellow Rail detection probability is imperfect. The detection probability that we estimated (0.63) is consistent with the range of detectability estimated for other secretive

Table 4. Effects of survey conditions on the number of Yellow Rails (Coturnicops noveboracensis) detected during night surveys $(n=150)$ in south-central Manitoba $(n=75$ survey points) at least once throughout the breeding season in 2010 or 2011, estimated using a generalized linear mixed model.

\begin{tabular}{|c|c|c|c|c|}
\hline Survey Covariate & $\beta$ Estimate & Standard Error & $\begin{array}{c}\text { Degrees } \\
\text { of Freedom }\end{array}$ & $P$ \\
\hline Intercept & 1.708 & 1.315 & 33 & 0.203 \\
\hline Year & 0.084 & 0.276 & 33 & 0.764 \\
\hline Time since sunset & -0.001 & 0.001 & 107 & 0.185 \\
\hline Temperature & -0.003 & 0.031 & 107 & 0.922 \\
\hline Julian date & -0.005 & 0.009 & 107 & 0.562 \\
\hline Beaufort wind speed & -0.104 & 0.098 & 107 & 0.289 \\
\hline Cloud cover & -0.085 & 0.069 & 107 & 0.218 \\
\hline Moon phase & -0.088 & 0.136 & 107 & 0.519 \\
\hline Moon visibility & -0.036 & 0.313 & 107 & 0.908 \\
\hline Moon phase*moon visibility & 0.024 & 0.138 & 107 & 0.862 \\
\hline
\end{tabular}


Table 5. AIC $\mathrm{A}_{\mathrm{c}}$ values for candidate models tested in program DOBSERV (Hines 2000) to explain variation in observer detection probability for Yellow Rail (Coturnicops noveboracensis) surveys conducted in south-central Manitoba in 2010-2011.

\begin{tabular}{lccccccc}
\hline \hline Model & Likelihood & DF & AIC & QAIC & AIC $_{c}$ & QAIC $_{c}$ & G-O-F \\
\hline $\mathrm{P}(.,)$. & -1.885 & 3 & 5.770 & 5.770 & 6.056 & 6.056 & 0.998 \\
$\mathrm{P}(., \mathrm{I})$ & -1.867 & 2 & 7.734 & 7.734 & 8.657 & 8.657 & 1.000 \\
\hline
\end{tabular}

marsh birds. Valente et al. (2011) estimated detection probabilities for Common Gallinule (Gallinula galeata), Least Bittern and Purple Gallinule (Porphyrio martinicus) at between 0.11 and 0.75 , depending on observer and environmental conditions. Budd and Krementz (2010) estimated Least Bittern detection probability at 0.16 and 0.58 in the 2 years of their study. Nonetheless, our estimated detection probability suggests there is a risk of classifying wetlands as not occupied by Yellow Rails when this species is present. Indeed, our approach of dropping plots at which Yellow Rails were never detected from the detectability analyses, although consistent with standard recommendations in the literature (e.g., Conway et al. 2004; Conway and Gibbs 2005; Rehm and Baldassarre 2007), might overestimate detectability. It is likely that Yellow Rails were present, but not detected, in other plots, and thus the risk of erroneously classifying occupied wetlands as unoccupied might be even higher than we have shown here.

Yellow Rail detection probability did not vary significantly with Julian date, but in both years the total number of Yellow Rails detected in the June-July survey was lower than in the May-June survey. Yellow Rail vocalization activity is typically high during incubation, and ceases upon hatching of the young (Lane 1962), although some individuals may continue vocalizing into July (Devitt 1939; Stenzel 1982) or August (Bookhout and Stenzel 1987; Robert and Laporte 1999). Although guidelines for Yellow Rail surveys in Manitoba suggest that, in the absence of any breeding information noting otherwise, surveys should be conducted no later than midJuly (Bazin and Baldwin 2007), the lower number of detections in the June-July survey suggests that it might be helpful to conduct surveys toward the first half of the breeding season (i.e., until approximately mid-June) to maximize the number of Yellow Rails detected. The primary vocalization period for Yellow Rails might differ at different latitudes. Studies conducted in other areas of the Yellow Rail breeding range should evaluate the appropriate survey period for Yellow Rails in that area.

Yellow Rail detections continued throughout the night, with a non-significant decreasing trend as the night progressed. Similarly, most studies and observations have noted that Yellow Rail vocal activity begins after total darkness and continues throughout the night (Devitt 1939; Gibbs et al.1991; Bookhout 1995). Prescott et al. (2002) found that peak nightly vocalization of Yellow Rails was during 00:00 to 01:59 hr. Our study reinforces these observations agreeing with Bazin and Baldwin's (2007) guidelines that Yellow Rail surveys should be restricted to between $1 \mathrm{hr}$ after sunset and $1 \mathrm{hr}$ prior to sunrise.

There were no significant effects of wind, temperature, cloud cover, moon phase, moon visibility, or an interaction between moon phase and moon visibility on the detection probability of Yellow Rails. Bart et al. (1984) and Prescott et al. (2002) also found that Yellow Rail vocalization rates were not significantly influenced by weather. Night surveys for Yellow Rail can be conducted during light to moderate wind speeds (Beaufort <4). Prescott et al. (2002) found that fewer Yellow Rails were detected during higher moon phases, but the authors suggest that this effect might have been spurious.

Observer detection probability for Yellow Rails was high (98\%) compared to estimates for the detection of other species of marsh birds. For example, mean observer detection probability of Black Rails was $76 \%$ (Conway et al. 2004). Similarly, Nadeau et al. (2008) found that the observer detection 
probability for several secretive marsh bird species was $75 \%$. Observer detection probability does not seem to be a factor in the number of Yellow Rails detected.

Yellow Rails appear to call fairly readily at night, relatively independently of most environmental conditions, and we found little evidence that call-broadcast improved detectability beyond the additional individuals that would be detected in a 10 -min passive listening survey. While it is possible that we detected some Yellow Rails only because of the call-broadcast segment of the survey, this could explain at most $17 \%$ of our detections, which is small relative to effects of call-broadcast on detectability of other secretive marsh birds. This suggests that surveys where call-broadcast is not feasible, such as volunteer surveys and breeding bird atlases, are still likely to result in good estimates of Yellow Rail abundances, as long as surveys are conducted during the prime calling period at night. Nonetheless, as call-broadcast surveys have been shown to increase detectability of Yellow Rails in other regions (e.g., Conway and Nadeau 2010), further studies should be conducted to evaluate under what conditions call-broadcast surveys contribute to efficient surveys.

\section{ACKNOWLEDGMENTS}

Project funding was provided by Manitoba Conservation's Sustainable Development Innovations Fund, Natural Sciences and Engineering Research Council, Canadian Foundation for Innovations, Manitoba Research Innovations Fund, and the Clayton H. Riddell Faculty of Environment, Earth and Resources. D. Furutani and K. Martin conducted all field work. We thank landowners for allowing us access to their properties. We thank two anonymous reviewers for their helpful comments.

\section{Literature Cited}

Allen, T., S. L. Finkbeiner and D. H. Johnson. 2004. Comparison of detection rates of breeding marsh birds in passive and playback surveys at Lacreek National Wildlife Refuge, South Dakota. Waterbirds 27: 277-281.

Alvo, R. and M. Robert. 1999. Committee on the Status of Endangered Wildlife in Canada (COSEWIC) assessment and status report on the Yellow Rail Coturnicops noveboracensis in Canada. COSEWIC, Ottawa, Ontario.
Arnold, T. W. 2010. Uninformative parameters and model selection using Akaike's Information Criterion. Journal of Wildlife Management 74: 1175-1178.

Bailey, L. L., J. D. Nichols and J. E. Hines. 2007. Exploring sampling design trade-offs in occupancy studies with imperfect detection: examples and software. Ecological Applications 17: 281-290.

Bart, J., R. A. Stehn, J. A. Herrick, N. A. Heaslip, T. A. Bookhout and J. R. Stenzel. 1984. Survey methods for breeding Yellow Rails. Journal of Wildlife Management 48: 1382-1386.

Bazin, R. and F. B. Baldwin. 2007. Canadian Wildlife Service standardized protocol for the survey of Yellow Rails (Coturnicops noveboracensis) in prairie and northern region. Environment Canada Report, Winnipeg, Manitoba.

Bookhout, T. A. 1995. Yellow Rail (Coturnicops noveboracensis). No. 139 in The Birds of North America (A. Poole and F. Gill, Eds.). Academy of Natural Sciences, Philadelphia, Pennsylvania; American Ornithologists' Union, Washington, D.C.

Bookhout, T. A. and J. R. Stenzel. 1987. Habitat and movements of breeding Yellow Rails. Wilson Bulletin 99: 441-447.

Brigham, M. 1994. Yellow Rail. Bird sounds of Canada vol. 1: loons to woodpeckers. Holborne Distributing Co. Ltd., Mount Albert, Ontario.

Budd, M. J. and D. G. Krementz. 2010. Habitat use by Least Bitterns in the Arkansas Delta. Waterbirds 33: 140-147.

Burnham, K. P. and D. R. Anderson. 2002. Model selection and multimodel inference: a practical information-theoretical approach. Springer-Verlag, New York, New York.

Committee on the Status of Endangered Wildlife in Canada (COSEWIC). 2001. COSEWIC assessment and status report on the Yellow Rail Coturnicops noveboracensis in Canada. COSEWIC, Ottawa, Ontario. www.sararegistry.gc.ca/species/speciesDetails_e. cfm?sid=574, accessed 7 January 2014.

Committee on the Status of Endangered Wildlife in Canada (COSEWIC). 2009. COSEWIC assessment and status report on the Yellow Rail Coturnicops noveboracensis in Canada. COSEWIC, Ottawa, Ontario. www.sararegistry.gc.ca/species/speciesDetails_e. cfm?sid=574, accessed 7 January 2014.

Conway, C. J. 2009. Standardized North American marsh bird monitoring protocols. Wildlife Research Report \#2009-02, U.S. Department of the Interior, Geological Survey, Arizona Cooperative Fish and Wildlife Research Unit, Tucson, Arizona.

Conway, C. J. and J. P. Gibbs. 2005. Effectiveness of callbroadcast surveys for monitoring marsh birds. Auk 122: 26-35.

Conway, C. J. and C. P. Nadeau. 2010. Effects of broadcasting conspecific and heterospecific calls on detection of marsh birds in North America. Wetlands 30: 358-368.

Conway, C. J., C. Sulzman and B. E. Raulston. 2004. Factors affecting detection probability of California 
black rails. Journal of Wildlife Management 68: 360370 .

Devitt, O. E. 1939. The Yellow Rail breeding in Ontario. Auk 56: 238-243.

Ecological Stratification Working Group. 1995. A national ecological framework for Canada. Report and national map at 1:7,500,000 scale. Agriculture and Agri-Food Canada, Research Branch, Centre for Land and Biological Resources Research and Environment Canada, State of the Environment Directorate, Ecozone Analysis Branch. Ottawa/Hull, Ontario.

Elliot, R. D. and R. I. G. Morrison. 1979. The incubation period of the Yellow Rail. Auk 96: 422-423.

Environmental Systems Research Institute (ESRI). 2010. ArcMap, v. 10.0. ESRI, Redlands, California.

Fryer, R. 1937. The Yellow Rail in southern Manitoba. Canadian Field-Naturalist 51: 41-42.

Gibbs, J. P. and S. M. Melvin. 1993. Call-response surveys for monitoring breeding waterbirds. Journal of Wildlife Management 57: 27-34.

Gibbs, J. P. and S. M. Melvin. 1997. Power to detect trends in waterbird abundance with call-response surveys. Journal of Wildlife Management 61: 1262-1267.

Gibbs, J. P., W. G. Shriver and S. M. Melvin. 1991. Spring and summer records of the Yellow Rail in Maine. Journal of Field Ornithology 62: 509-516.

Glahn, J. F. 1974. Study of breeding rails with recorded calls in north-central Colorado. Wilson Bulletin 86: 206-214.

Herkert, J. R. 1995. An analysis of Midwestern breeding bird population trends: 1966-1993. American Midland Naturalist 134: 41-50.

Hines, J. E. 2000. DOBSERV: a double-observer approach for estimating detection probability and abundance from avian point counts. http://www. mbr-pwrc.usgs.gov/software/dobserv.shtml, accessed 7 January 2014.

Holland, G. E. and P. Taylor. 2003. Yellow rail. Page 156 in The Birds of Manitoba (P. Taylor, Ed.). Manitoba Naturalists Society, Winnipeg, Manitoba.

Johnson, R. R. and J. J. Dinsmore. 1986. The use of taperecorded calls to count Virginia Rails and Soras. Wilson Bulletin 98: 303-306.

Lane, F. 1962. Nesting of the Yellow Rail in southwestern Manitoba. Canadian Field-Naturalist 76: 189-191.

Legare, M. L., W. R. Eddleman, P. A. Buckley and C. Kelly. 1999. The effectiveness of tape playback in estimating black rail density. Journal of Wildlife Management 63: 116-125.

Lor, S. and R. A. Malecki. 2002. Call-response surveys to monitor marsh bird population trends. Wildlife Society Bulletin 30: 1195-1201.

MacKenzie, D. I. 2005. What are the issues with presence-absence data for wildlife managers? Journal of Wildlife Management 69: 849-860.

MacKenzie, D. I. and J. A. Royle. 2005. Designing occupancy studies: general advice and allocating survey effort. Journal of Applied Ecology 42: 1105-1114.

MacKenzie, D. I., J. D. Nichols, G. B. Lachman, S. Droege, J. A. Royle and C. A. Langtimm. 2002.
Estimating site occupancy rates when detection probabilities are less than one. Ecology 83: 22482255.

MacKenzie, D. I., J. D. Nichols, J. A. Royle, K. H. Pollock, L. L. Bailey and J. E. Hines. 2006. Occupancy estimation and modeling: inferring patterns and dynamics of species occurrence. Academic Press, Burlington, Massachusetts.

Manitoba Land Initiative. 2001. Land use/land cover map layers. Manitoba Land Initiative, Winnipeg, Manitoba. http://mli2.gov.mb.ca/, accessed 7 January 2014.

Manitoba Land Initiative. 2002. Land use/land cover map layers. Manitoba Land Initiative, Winnipeg, Manitoba. http://mli2.gov.mb.ca/, accessed 7 January 2014.

Mougeot, F. and V. Bretagnolle. 2000. Predation risk and moonlight avoidance in nocturnal seabirds. Journal of Avian Biology 31: 376-386.

Nadeau, C. P., C. J. Conway, B. S. Smith and T. E. Lewis. 2008. Maximizing detection probability of wetlanddependent birds during point-count surveys in northwest Florida. Wilson Journal of Ornithology 120: 513-518.

Nichols, J. D., J. E. Hines, J. R. Sauer, F. W. Fallon, J. E. Fallon and P. J. Heglund. 2000. A double-observer approach for estimating detection probability and abundance from point counts. Auk 117: 393-408.

Popper, K. J. and M. A. Stern. 2000. Nesting ecology of Yellow Rails in southcentral Oregon. Journal of Field Ornithology 71: 460-466.

Prescott, D. R. C., M. R. Norton and I. M. G. Michaud. 2002. Night surveys of yellow rails, Coturnicops noveboracensis, and Virginia rails, Rallus limicola, in Alberta using call playbacks. Canadian Field Naturalist 116: 408-415.

Quinn, G. P. and M. J. Keough. 2002. Experimental design and data analysis for biologists. Cambridge University Press, Cambridge, U.K.

Rehm, E. M. and G. A. Baldassarre. 2007. Temporal variation in detection of marsh birds during broadcast of conspecific calls. Journal of Field Ornithology 78 : 56-63.

Ribic, C. A., S. J. Lewis, S. Melvin, J. Bart and B. Peterjohn. 1999. Proceedings of the marsh bird monitoring workshop. Unpublished report, U.S. Department of the Interior, Fish and Wildlife Service, Region 3, Laurel, Maryland.

Robert, M. 1997. A closer look: Yellow Rail. Birding 29: 282-290.

Robert, M. and P. Laporte. 1999. Numbers and movements of Yellow Rails along the St. Lawrence River, Québec. Condor 101: 667-671.

SAS Institute, Inc. 2008. SAS statistical software v. 9.2. SAS Institute, Inc., Cary, North Carolina.

Sauer, J. R., J. E. Hines, J. E. Fallon, K. L. Pardieck, D. J. Ziolkowski, Jr. and W. A. Link. 2012. The North American breeding bird survey, results and analysis 1966-2011, v. 07.03.2013. U.S. Department of the Interior, Geological Survey, Patuxent Wildlife Research Center, Laurel, Maryland. 
Smith, A. C., N. Koper, C. M. Francis and L. Fahrig. 2009. Confronting collinearity: comparing methods for disentangling the effects of habitat loss and fragmentation. Landscape Ecology 24: 1271-1285.

Spear, L. B., S. B. Terrill, C. Lenihan and P. Delevoryas. 1999. Effects of temporal and environmental factors on the probability of detecting California Black Rails. Journal of Field Ornithology 70: 465-480.

Stenzel, J. R. 1982. Ecology of breeding Yellow Rails at Seney National Wildlife Refuge. M.S. Thesis, Ohio State University, Columbus.

Stermin, A. N., A. David and E. Sevianu. 2013. An evaluation of acoustic monitoring methods for a Water Rail (Rallus aquaticus) population in a large reed bed. Waterbirds 36: 463-469.

Stewart, R. E. and H. A. Kantrud. 1971. Classification of natural ponds and lakes in the glaciated prairie re- gion. Resource Publication 92, U.S. Department of the Interior, Bureau of Sport Fisheries and Wildlife, Fish and Wildlife Service, Washington, D.C.

Tyre, A. J., B. Tenhumberg, S. A. Field, D. Niejalke, K. Parris and H. P. Possingham. 2003. Improving precision and reducing bias in biological surveys: estimating false-negative error rates. Ecological Applications 13: 1790-1801.

U.S. Fish and Wildlife Service. 2002. Birds of conservation concern 2002. Unpublished report, U.S. Department of the Interior, Fish and Wildlife Service, Division of Migratory Bird Management, Arlington, Virginia.

Valente, J. J., S. L. King and R. R. Wilson. 2011. Distribution and habitat associations of breeding secretive marsh birds in Louisiana's Mississippi alluvial valley. Wetlands 31: 1-10. 